\title{
Synthesis and alkylation of some [1,2,4]triazolo[4,3-b]tetrazines
}

\author{
Zoltán Novák, Antal Csámpai, and András Kotschy* \\ Department of General and Inorganic Chemistry, Eötvös Loránd University, \\ H-1117 Budapest, Pázmány P. s. 1/A, Hungary \\ E-mail: kotschy@para.chem.elte.hu
}

Dedicated to Gurnos Jones on the occasion of his $70^{\text {th }}$ birthday (received 05 Feb 00; accepted 20 Aug 00; published on the web 28 Aug 00)

\begin{abstract}
Two [1,2,4]triazolo[4,3-b]tetrazines (3 and 6) were synthesised and alkylated using various reagents. The formation of the ethylated $[1,2,4]$ triazolo[4,3-b]tetrazinium salts $(9,10 a-b)$ and their structure was unambiguously established using correlational NMR spectroscopy. The product distribution was interpreted on the basis of quantum chemical calculations. The triazolotetrazinium salts $(9,10 a-b)$ were found to dealkylate on workup to give the corresponding tetrafluoroborate salts $(7,8)$.
\end{abstract}

Keywords: Triazalotetrazines synthesis, thiazolotetrazinium salts, quantum chemical calculations

\section{Introduction}

Condensed heterocyclic systems are of considerable interest not only because of their potential biological activity but also because of their value as synthons in organic transformations. Azolopyridinium salts, which are the precursors of hetaryldienes, ${ }^{1}$ can be prepared by the selective alkylation of the neutral parent polycycles or by direct ring closure. ${ }^{2,3}$ The selectivity in the alkylation of triazolopyridines, tetrazolopyridines and their benzologues (i.e. preference of one azole nitrogen over the others) was interpreted by frontier molecular orbital interactions and electronic properties, supported by quantum chemical calculations. ${ }^{2-4}$

As part of our ongoing research on the "inverse electron-demand" Diels-Alder reaction of electron rich dienes and tetrazines ${ }^{3-5}$ we were interested in the synthesis of new electron deficient tetrazine derivatives. Extension of the alkylation strategy to condensed azolotetrazines (e.g. to the known ${ }^{6}[1,2,4]$ triazolo[4,3-b]tetrazines) could in principle lead to azolotetrazinium salts that would be expected to possess an increased reactivity due to their more electron deficient nature. The envisaged approach is also of theoretical interest through establishment of the effect of the increased number of nitrogen atoms in the molecule on the selectivity of the alkylation reaction. 


\section{Results and Discussion}

6-(3,5-Dimethylpyrazol-1-yl)-[1,2,4]triazolo[4,3-b]tetrazine (3) was prepared in two steps from the easily accessible 3,6-bis(3,5-dimethylpyrazol-1-yl)-tetrazine (1) through the hydrazino derivative (2) following literature procedures. ${ }^{6}$ As the second nitrogen of the pyrazole substituent might in principle interfere in the alkylation process of 3 we also prepared its morpholino analogue (6) where conjugation of the morpholine nitrogen with the tetrazine moiety ${ }^{7}$ makes it an unlikely site for electrophilic attack. The synthesis of 6 also starts with 3,6-bis(3,5dimethylpyrazol-1-yl)-tetrazine (1) which through sequential displacement of the pyrazole rings with morpholine ${ }^{7}$ (4) and hydrazine gives 3-hydrazino-6-morpholino-tetrazine (5), which is converted to 6-morpholino-[1,2,4]triazolo[4,3-b]tetrazine (6) on treatment with triethyl orthoformate.

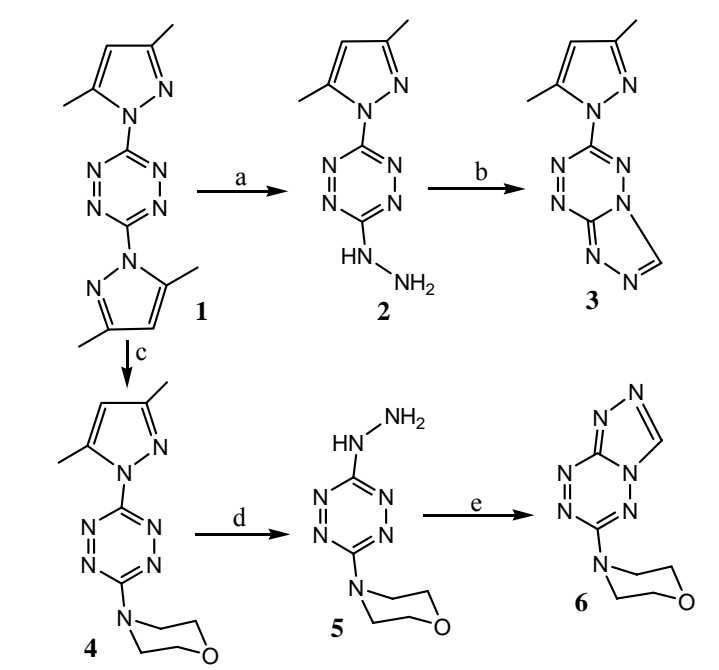

a, $\mathrm{NH}_{2} \mathrm{NH}_{2}$, EtOH; b, $\mathrm{HC}(\mathrm{OEt})_{3}$; c, morpholine, EtOH; d, $\mathrm{NH}_{2} \mathrm{NH}_{2}$; e $\mathrm{HC}(\mathrm{OEt})_{3}$

The light yellow triazolotetrazines 3 and 6 were alkylated using a series of reagents ranging from the soft methyl iodide through dimethyl sulfate to the hard triethyloxonium tetrafluoroborate. In each case the alkylation of the heterocycles proceeded readily accompanied by the change of the colour of the reaction mixture to purple. Evaporation of the solvent followed by conversion of the formed salts to their tetrafluoroborate analogues ${ }^{8}$ resulted in deep red solids 7 and 8 in good yield. Spectroscopic analysis of the products revealed however that 7 and 8 contained no alkyl moiety but were $\mathrm{HBF}_{4}$ salts of the parent heterocycles. As one can detect the consumption of the starting material (3 and 6) during the alkylation step we assume that the expected N-alkyl-triazolotetrazinium salts are formed as intermediates but, unlike their triazolopyridine analogues ${ }^{2}$, lose their alkyl group on workup, probably due to their inherent alkylating ability. 


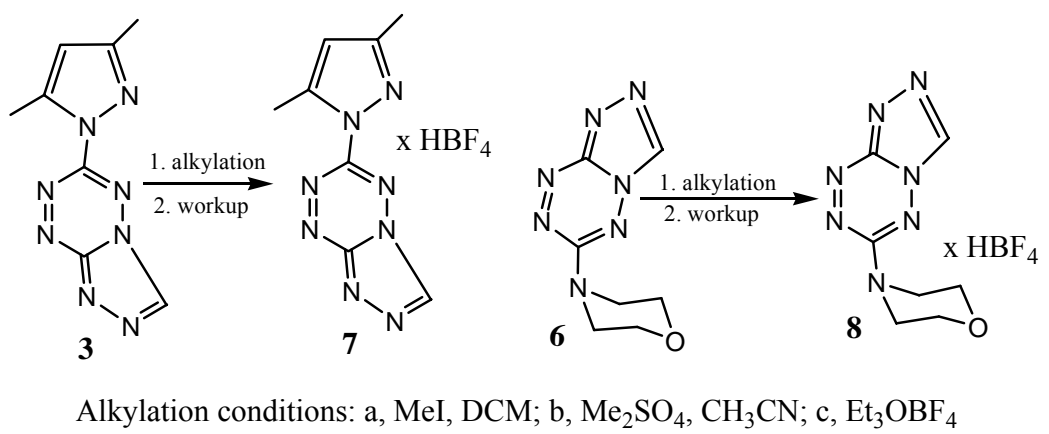

To prove the formation of the alkyl-triazolotetrazinium salts and to obtain information on the selectivity of the alkylation, the triazolotetrazines $(3,6)$ were reacted with triethyloxonium tetrafluoroborate in deuterated acetonitrile at ambient temperature and the reaction was monitored by NMR spectroscopy. We found in both cases that consumption of the starting material is accompanied by the emergence of a set of new signals.

Detectable alkylation of 3 occurred only on the pyrazole ring yielding 9, the structure of which was unambiguously established by DNOE experiments. Mutual NOE responses excluding other possible structures were measured between the methylene protons of the ethyl group and the adjacent methyl substituent on the pyrazole ring (15-18\%), as well as between the methyl protons of the ethyl group and $\mathrm{C}^{3} \mathrm{H}$ on the triazole moiety (2-4\%). Since the slow rotation of the alkylated pyrazole ring causes a considerable broadening of the ${ }^{1} \mathrm{H}$ NMR signals, N-H long range correlations (through 2 and 3 bonds) could not be detected in the 2D-HMBC spectrum making it impossible to obtain ${ }^{15} \mathrm{~N}$ NMR data for 9 .

Alkylation of the morpholino derivative 6 took place on the triazole moiety resulting a 7:3 mixture of the expected $\mathrm{N}^{2}$ - and $\mathrm{N}^{1}$ - alkylated products (10a and 10b). The structures of 10a and b were determined by ${ }^{1} \mathrm{H}^{13} \mathrm{C}$ HMBC and DNOE measurements. In the major product (10a) the three-bond correlation between the corresponding protons and carbons of the $\mathrm{CH}_{2}$ group and the $\mathrm{C}^{3} \mathrm{H}$ unit in the triazole ring was obvious, but no correlation was observed between the $\mathrm{CH}_{2}$ protons and $\mathrm{C}^{9}$ being separated by four bonds. This carbon $\left(\mathrm{C}^{9}\right)$ was assigned through its threebond correlation with $\mathrm{C}^{3} \mathrm{H}$. Mutual NOEs between the $\mathrm{CH}_{2}$ protons and $\mathrm{C}^{3} \mathrm{H}$ provide further evidence of the $\mathrm{N}^{2}$-alkylated structure.

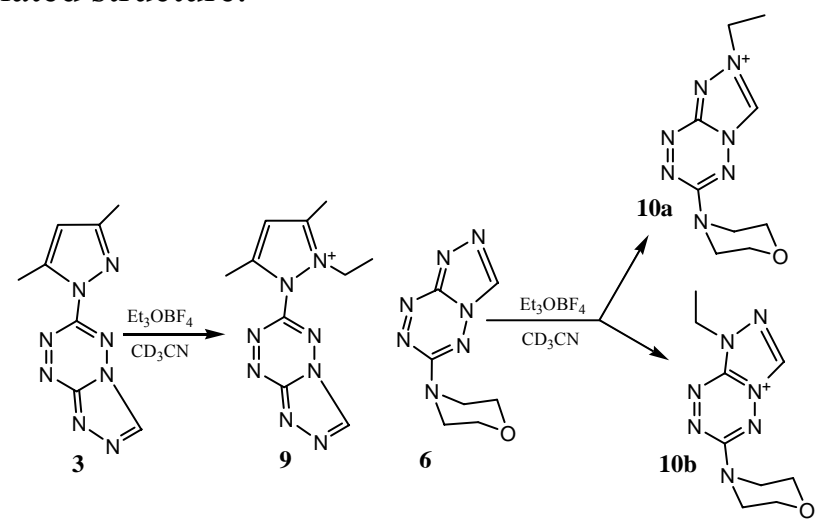

In the minor product $(10 \mathrm{~b}) \mathrm{N}^{1}$-alkylation is supported by the three-bond correlation between the $\mathrm{CH}_{2}$ protons and $\mathrm{C}^{9}$, the lack of correlation between these protons and $\mathrm{C}^{3}$, and the steric compression shift of the $\mathrm{C}^{9}$ signal $(5.0 \mathrm{ppm})$ relative to that of $10 \mathrm{a}\left(\delta \mathrm{C}^{9}=145.4\right.$ for $10 \mathrm{a}$ and 
$140.4 \mathrm{ppm}$ for $10 \mathrm{~b})$. The ${ }^{15} \mathrm{~N}$-resonances of the triazole and morpholine rings $\left(\mathrm{N}^{1}, \mathrm{~N}^{2}, \mathrm{~N}^{4}\right.$ and $\mathrm{N}^{10}$ ) were detected and assigned for $10 \mathrm{a}$ and $\mathrm{b}$ by means of ${ }^{1} \mathrm{H}_{-}{ }^{15} \mathrm{~N}-\mathrm{HMBC}$ measurements. The assignation of the relatively upfield-shifted nitrogens is based on their three-bond correlation with the $\mathrm{CH}_{3}$ protons of the attached ethyl group. It is worth mentioning that the increased delocalization of the lone pair of $\mathrm{N}^{4}$ in $10 \mathrm{~b}$ compared to $10 \mathrm{a}$ (as predicted by Clars aromaticity theory) is nicely reflected by the ${ }^{15} \mathrm{~N}$ shifts (179 ppm for $10 \mathrm{a}$ vs. $191 \mathrm{ppm}$ for $10 \mathrm{~b}$ ).

In order to study the nature of the alkylation a series of quantum chemical calculations ${ }^{9}$ were carried out on the triazolopyridines 3 and 6 and their methylated derivatives. The calculated orbital distribution of the starting materials ${ }^{10}$ and the hard nature of the oxonium salt suggest that the frontier orbital control over the course of the alkylation is minimal. The calculations also reveal (Table 1) that the charge distribution is fairly even along both molecules (3 and 6), with the triazole nitrogens $\mathrm{N}^{1}$ and $\mathrm{N}^{2}$ bearing similar charges and being slightly more negative than the other nitrogens, except for $\mathrm{N}^{5}$ in 6 .

The finding that the alkylated triazolotetrazinium salts are good alkylating agents would suggest that the product distribution is governed more likely by thermodynamic than kinetic factors. To estimate the stability of the potential products the heats of formation of the methylated triazolotetrazinium salts were calculated and compared. The results, summarised in Table 1 show that if the process runs under thermodynamic control, then formation of $\mathrm{N}^{1}$ and $\mathrm{N}^{2}$ methylated products has about the same probability (slightly favouring $\mathrm{N}^{1}$ alkylation in both cases), while methylation on any of the other nitrogen atoms is disfavoured.

Finally common sense dictates that alkylation of $\mathrm{N}^{2}$ should be sterically favoured over alkylation of $\mathrm{N}^{1}$.
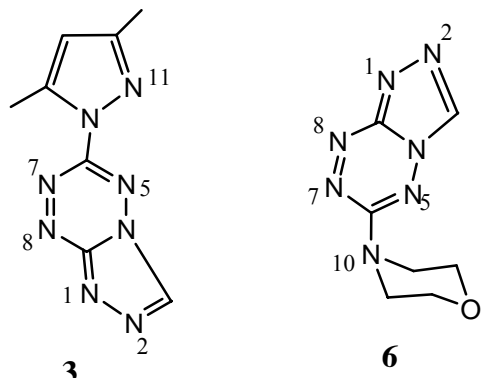

Table 1. Calculated charges on the nitrogen atoms in triazolo[4,3-b]tetrazines 3 and 6 and the relative heats of formations $(\mathrm{kcal} / \mathrm{mol})$ of the appropriate methylated triazolotetrazinium cations $\left(\mathrm{N}^{1}-\mathrm{N}^{11}\right.$ denoting the site of methylation)

\begin{tabular}{|c|c|c|c|c|c|c|}
\hline 3 & N1 & $\mathrm{N} 2$ & N5 & N7 & N8 & N11 \\
\hline Charge & $-0,41$ & $-0,39$ & $-0,30$ & $-0,34$ & $-0,29$ & $-0,35$ \\
\hline $\mathrm{DDH}_{\mathrm{f}}($ methylated $)$ & 0,354 & 0,000 & 28,261 & 29,627 & 18,734 & 7,183 \\
\hline 6 & N1 & $\mathrm{N} 2$ & N5 & N7 & N8 & N10 \\
\hline Charge & $-0,41$ & $-0,40$ & $-0,41$ & $-0,33$ & $-0,29$ & ---- \\
\hline $\mathrm{DDH}_{\mathrm{f}}$ (methylated) & 0,223 & 0,000 & 35,755 & 30,782 & 29,409 & 32,226 \\
\hline
\end{tabular}


Comparison of the calculated results with the experimental findings reveals, that contrary to the analogous transformation of the related triazolopyridin ${ }^{4}$ system, the factors governing the alkylation of $[1,2,4]$ triazolo[4,3-b]tetrazines-due probably to the increased number of nitrogens in the molecule - are complex and can not be attributed to a single kinetic, thermodynamic or steric effect.

The absence of selectivity and the alkylating nature of the products make the applicability of triazolotetrazinium salts in "inverse electron-demand" Diels-Alder reactions limited. Attempts to prepare selectively alkylated analogues through direct ring closure reactions are in progress in our laboratory.

\section{Experimental Section}

General Procedures. The NMR spectra were recorded on a Bruker DRX 500 spectrometer at $500.13\left({ }^{1} \mathrm{H}\right), 125.76\left({ }^{13} \mathrm{C}\right)$ and $50.68\left({ }^{15} \mathrm{~N}\right) \mathrm{MHz}$, in deuterochloroform (unless otherwise stated) with the deuterium signal of the solvent as the lock and TMS as internal reference. Direct $\mathrm{C}-\mathrm{H}$ correlations were obtained in each case by 2D-HMQC spectra. Since direct measurement of nitrogens was impossible in $\mathrm{CD}_{3} \mathrm{CN},{ }^{15} \mathrm{~N}-\mathrm{NMR}$ signals were indirectly obtained with the same instrument by detection of protons (2D-HMBC). The chemical shifts are given upfield from liquid nitromethane as external reference. The IR spectra were obtained on a Bruker IFS-55 FTIR spectrometer. The melting points were determined on a Büchi apparatus and are uncorrected. We were unable to obtain reasonable nitrogen analysis for the prepared new compounds, probably due to their high nitrogen content.

3-(3,5-Dimethylpyrazol-1-yl)-6-(morpholin-4-yl)-1,2,4,5-tetrazine (4). 2,16g (8mmol) 3,6-bis(3,5-dimethyl-pyrazol-1-yl)-(1,2,4,5)tetrazine was dissolved in toluene $(50 \mathrm{ml})$. To the tetrazine solution morpholine $(696 \mathrm{mg}, 8 \mathrm{mmol}, 696 \mathrm{ll})$ was added. The reaction mixture was stirred for 6 hours at $25^{\circ} \mathrm{C}$. Excess of toluene was removed by distillation under reduced pressure.. The remaining red tetrazine was recrystallized from $\mathrm{n}$-heptane, resulting in $1.60 \mathrm{~g}$ pure product. Yield: 76.6\%. mp.: $114^{\circ} \mathrm{C} ;{ }^{1} \mathrm{H}$ NMR $\delta 2.33(\mathrm{~s}, 3 \mathrm{H}), 2.55(\mathrm{~s}, 3 \mathrm{H}), 3.85(\mathrm{t}, J=4.9 \mathrm{~Hz}, 4 \mathrm{H}), 4.01(\mathrm{t}, J=$ $4.9 \mathrm{~Hz}, 4 \mathrm{H}), 6.08(\mathrm{~s}, 1 \mathrm{H}) ;{ }^{13} \mathrm{C}$ NMR $\delta 13.9,14.1,44.4,66.8,110.1,142.3,152.6,157.4,160.9$; $\mathrm{IR}(\mathrm{KBr})_{v \max } 2990,2918,2858,1572,1534,1484,1450,1396,1360,1305,1261,1121,1084$, $944 \mathrm{~cm}^{-1}$; Anal. Calcd for $\mathrm{C}_{11} \mathrm{H}_{15} \mathrm{~N}_{7} \mathrm{O}$ : C, 50.57; H, 5.79. Found: C, 50.75; H, 5.92 .

3-Hydrazino-6-(morpholin-4-yl)-1,2,4,5-tetrazine (5). $0.6 \mathrm{~g}$ (2.29mmol) 4 was dissolved in $10 \mathrm{ml}$ acetonitrile at $25^{\circ} \mathrm{C}$ and $0.2 \mathrm{ml} 98 \%$ hydrazine-hydrate was added. The reaction mixture was stirred for $1.5 \mathrm{~h}$, then the precipitated red solid was filtered. The product was recrystallized from acetonitrile. Yield: $0.43 \mathrm{~g}, 82 \% . \mathrm{mp} 186{ }^{\circ} \mathrm{C} ;{ }^{1} \mathrm{H} \mathrm{NMR} \delta 3.81(\mathrm{t}, J=4.9 \mathrm{~Hz}, 4 \mathrm{H}), 3.84(\mathrm{t}, J=$ $4.9 \mathrm{~Hz}, 4 \mathrm{H}), 3.97(\mathrm{~d}, 2 \mathrm{H}), 6.39(\mathrm{t}, 1 \mathrm{H}) ;{ }^{13} \mathrm{C} \mathrm{NMR} \delta 44.8,66.8,151.4,162.5 . \mathrm{IR}(\mathrm{KBr}) v_{\max } 2979$, 1920, 2867, 1642, 1503, 1444, 1348, 1305, 1248, 1119, 1065, 1039, 969, $938 \mathrm{~cm}^{-1}$; Anal. Calcd for $\mathrm{C}_{6} \mathrm{H}_{11} \mathrm{~N}_{7} \mathrm{O}: \mathrm{C}, 36.54 ; \mathrm{H}, 5.62$. Found: $\mathrm{C}, 36.54 ; \mathrm{H}, 5.88$. We were unable to get a correct 
carbon analysis even after several recrystallisation-drying cycles, while the melting point and the spectroscopic properties were already unchanged.

6-(Morpholin-4-yl)-[1,2,4]triazolo[4,3-b][1,2,4,5]tetrazine (6). $0.197 \mathrm{~g}(1 \mathrm{mmol}) 5$ and a catalytic amount of p-toluene-sulfonic acid was added to triethoxymethane $(1.6 \mathrm{ml})$. The reaction mixture was stirred at $60^{\circ} \mathrm{C}$ for $2 \mathrm{~h}$. The orange solid was filtered off and washed with diethyl ether. Yield: $81 \%$ (0.167g). mp $135{ }^{\circ} \mathrm{C} ;{ }^{1} \mathrm{H}$ NMR $\delta 3.87$ (t, J = 5.0 Hz, 4H), 3.96 (br, 4H), 8.72 $(\mathrm{s}, 1 \mathrm{H}) ;{ }^{13} \mathrm{C}$ NMR $\delta 45.2,66.6,136.0,150.2,155.4$; IR(KBr) $v_{\max } 3128,2972,2866,1542,1459$, $1371,1278,1259,1229,1115,1017,957,922,686 \mathrm{~cm}^{-1}$; Anal. Calcd for $\mathrm{C}_{7} \mathrm{H}_{9} \mathrm{~N}_{7} \mathrm{O}: \mathrm{C}, 40.58 ; \mathrm{H}$, 4.38. Found: C, 36.14; H, 4.23.

6-(3,5-Dimethylpyrazol-1-yl)-[1,2,4]triazolo[4,3-b][1,2,4,5]tetrazinium tetrafluoroborate (7). $0.043 \mathrm{~g}(0.2 \mathrm{mmol})$ tetrazine 3 was dissolved in acetonitrile $(1 \mathrm{ml})$ and alkylating reagent (triethyloxonium tetrafluoroborate, methyl iodide or dimethyl sulfate, $0.2 \mathrm{mmol}$ ) was added to the solution; it was then stirred for $2 \mathrm{~h}$ at $60^{\circ} \mathrm{C}$. The excess of solvent was evaporated, then the remaing red oil was dissolved in $1 \mathrm{ml}$ water. $\mathrm{HBF}_{4}(1 \mathrm{ml})$ was added to the aqueous solution and it was extracted with nitromethane $(10 \mathrm{ml})$. The organic phase was separated, dried and concentrated under reduced pressure to give 7 as a red solid.

6-(Morpholin-4-yl)-[1,2,4]triazolo[4,3-b][1,2,4,5]tetrazinium tetrafluoroborate (8). 0.041g $(0.2 \mathrm{mmol})$ tetrazine 6 was dissolved in acetonitrile $(1 \mathrm{ml})$ and alkylating reagent (triethyloxonium tetrafluoroborate, methyl iodide or dimethyl sulfate, $0.2 \mathrm{mmol}$ ) was added to the solution; it was then stirred for $2 \mathrm{~h}$ at $60^{\circ} \mathrm{C}$. The excess of solvent was evaporated, then the remaing red oil was dissolved in $1 \mathrm{ml}$ water. $\mathrm{HBF}_{4}(1 \mathrm{ml})$ was added to the aqueous solution and it was extracted with nitromethane $(10 \mathrm{ml})$. The organic phase was separated, dried and concentrated under reduced pressure to give 8 as a a red solid. ${ }^{1} \mathrm{H}-\mathrm{NMR} \delta 3.81(\mathrm{~m}, 4 \mathrm{H}), 4.38(\mathrm{br}, 4 \mathrm{H}), 10.79(\mathrm{~s}, 1 \mathrm{H})$; IR(KBr) $v_{\max } 3130,2864,1587,1449,1369,1286,1254,1229,1059,924,661 \mathrm{~cm}^{-1}$.

Alkylation of the $[1,2,4]$ triazolo[4,3-b][1,2,4,5]tetrazines (3 and 6$)$. $0.041 \mathrm{~g}(0.2 \mathrm{mmol}) 6$ or $0.043 \mathrm{~g}(0.2 \mathrm{mmol}) 3$ was dissolved in deuteroacetonitrile $(1 \mathrm{ml})$. Triethyloxonium tetrafluoroborate $(0.04 \mathrm{~g}, 0.2 \mathrm{mmol})$ was added and the reaction mixtures were stirred for $2 \mathrm{~h}$ at $25^{\circ} \mathrm{C}$.

9. ${ }^{1} \mathrm{H}-\mathrm{NMR}\left(\mathrm{CD}_{3} \mathrm{CN}\right) \delta 1.72(\mathrm{br}, 3 \mathrm{H}), 2.37$ (br, 3H), $2.63(\mathrm{br}, 3 \mathrm{H}), 4.84(\mathrm{br}, 2 \mathrm{H}), 6.43(\mathrm{~s}, 1 \mathrm{H})$, $10.53(\mathrm{~s}, 1 \mathrm{H}) ;{ }^{13} \mathrm{C}-\mathrm{NMR}\left(\mathrm{CD}_{3} \mathrm{CN}\right) \delta 13.6,14.2,14.7,52.4,114.3,137.3,148.6,151.9,152.5$, 154.5 .

10a. ${ }^{1} \mathrm{H}-\mathrm{NMR}\left(\mathrm{CD}_{3} \mathrm{CN}\right) \delta 1.65(\mathrm{t}, 3 \mathrm{H}, J=7.5 \mathrm{~Hz}), 3.84(\mathrm{br}, 4 \mathrm{H}), 4.3(\mathrm{br}, 4 \mathrm{H}), 4.67(\mathrm{q}, 2 \mathrm{H}, J=7.5$ $\mathrm{Hz}), 9.78(\mathrm{~s}, 1 \mathrm{H}) ;{ }^{13} \mathrm{C}-\mathrm{NMR}\left(\mathrm{CD}_{3} \mathrm{CN}\right) \delta 15.6\left(\mathrm{CH}_{3}\right), 46.0\left(\mathrm{NCH}_{2}\right.$-morpholine), $51.6\left(\mathrm{CH}_{2}\right.$-ethyl), $66.8\left(\mathrm{OCH}_{2}\right.$-morpholine), $135.0\left(\mathrm{C}^{3}\right), 145.4\left(\mathrm{C}^{9}\right), 156.6\left(\mathrm{C}^{6}\right) ;{ }^{15} \mathrm{~N}-\mathrm{NMR}\left(\mathrm{CD}_{3} \mathrm{CN}\right) \delta 93\left(\mathrm{~N}^{1}\right), 151$ $\left(\mathrm{N}^{2}\right), 179\left(\mathrm{~N}^{4}\right), 287\left(\mathrm{~N}^{10}\right)$.

10b. ${ }^{1} \mathrm{H}-\mathrm{NMR}\left(\mathrm{CD}_{3} \mathrm{CN}\right) \delta 1.69(\mathrm{t}, 3 \mathrm{H}, J=7.5 \mathrm{~Hz}), 3.85(\mathrm{br}, 4 \mathrm{H}), 4.3(\mathrm{br}, 4 \mathrm{H}), 4.95(\mathrm{q}, 2 \mathrm{H}, J=7.5$ $\mathrm{Hz}), 9.15(\mathrm{~s}, 1 \mathrm{H}) ;{ }^{13} \mathrm{C}-\mathrm{NMR}\left(\mathrm{CD}_{3} \mathrm{CN}\right) \delta 14.3\left(\mathrm{CH}_{3}\right), 46.0\left(\mathrm{NCH}_{2}\right.$-morpholine), $48.0\left(\mathrm{CH}_{2}\right.$-ethyl), $66.8\left(\mathrm{OCH}_{2}\right.$-morpholine), $136.3\left(\mathrm{C}^{3}\right), 140.4\left(\mathrm{C}^{9}\right), 158.7\left(\mathrm{C}^{6}\right) ;{ }^{15} \mathrm{~N}-\mathrm{NMR}\left(\mathrm{CD}_{3} \mathrm{CN}\right) \delta 159\left(\mathrm{~N}^{2}\right), 175$ $\left(\mathrm{N}^{1}\right), 191\left(\mathrm{~N}^{4}\right), 287\left(\mathrm{~N}^{10}\right)$. 


\section{Acknowledgements}

The financial support of the Hungarian Scientific Research Fund (OTKA F025801) is gratefully acknowledged. The authors are grateful to Mrs. Hedvig Medzihradszky-Schweger for the elementary analyses.

\section{References}

1. Hajós, Gy.; Kotschy, A. Acta Chimica Slovenica 1998, 45, 285.

2. Kotschy, A.; Hajós, Gy.; Messmer, A.; Jones, G. Tetrahedron 1996, 52, 1399 and references therein.

3. Kotschy, A.; Hajós, Gy.; Messmer, A. J. Org. Chem. 1995, 60, 4919.

4. Jones, G.; Richardson, C.M.; Yates, P.C.; Hajós, Gy.; Timári, G. Tetrahedron 1993, 49, 4307.

5. Kotschy, A.; Novák, Z.; Vincze, Z.; Smith, D.M.; Hajós, Gy. Tetrahedron Lett. 1999, 40, 6313 and references therein.

6. Chavez, D.E.; Hiskey, M.A. J. Heterocycl. Chem. 1998, 35, 1329. (b) Ershov, V.A.; Postovskii, I.Y. Khim. Geterosikl. Soedin. 1968, 4, 1134.

7. Glidewell, C.; Lightfoot, P.; Royles, B.J.L.; Smith, D.M., J. Chem. Soc., Perkin Trans. 2 1997, 1167.

8. The tetrafluoroborate salts were found to be superior to other analogues both in terms of their stability and crystallisation ability. See also Ref. 1.

9. Calculations were carried out with the Gaussian98w program package. Geometries were optimised on the $a b$ initio level using the $3-21 \mathrm{G}$ basis set.

10. The first molecular orbital with a considerable contribution from the "in plane" atomic orbitals of any of the triazole nitrogens, lies at $1.88 \mathrm{eV}$ (3) and $1.83 \mathrm{eV}$ (6) below the HOMO orbital, far too low to make their effect substantial. 